\section{Tuning efficiency of the 4-exo-trig cyclization by the electronic effect: ring closure of 3,3-difluoro-4-pentenyl carbon radicals and synthesis of a gem-difluorocyclobutane nucleoside $\dagger$}

\author{
Hiroki Kumamoto, ${ }^{* a}$ Sachiko Kawahigashi, ${ }^{a}$ Hiromi Wakabayashi, ${ }^{a}$ Tomohiko Nakano, ${ }^{a}$ \\ Tomoko Miyaike, ${ }^{a}$ Yasuyuki Kitagawa, ${ }^{a}$ Hiroshi Abe, ${ }^{b}$ Mika Ito, ${ }^{b}$ Kazuhiro Haraguchi, ${ }^{a}$ \\ Jan Balzarini, ${ }^{c}$ Masanori Baba ${ }^{d}$ and Hiromichi Tanaka ${ }^{a}$
}

Received 14th August 2012, Accepted 20th September 2012

DOI: $10.1039 / \mathrm{c} 2 \operatorname{cc} 35876 \mathrm{j}$

4-exo-trig Cyclization reaction of a 4-pentenyl carbon radical containing the gem-difluoromethylene moiety adjacent to a radical accepting $\alpha, \beta$-unsaturated ester was found to proceed efficiently to furnish a novel gem-difluorocyclobutane derivative. The cyclized product could be transformed into a gem-difluoromethylene analogue of oxetanocin $\mathbf{T}$.

Oxetanocin A $(\mathbf{1})^{1}$ is a nucleoside antibiotic isolated from Bacillus megaterium (Fig. 1). Due to the unique four-membered oxetanose moiety conferring promising anti-viral properties, ${ }^{2}$ considerable efforts have been devoted to the synthesis of $\mathbf{1}$, and its base- or sugar-modified derivatives. ${ }^{3}$ Interestingly, the thymine analogue of oxetanocin $\mathrm{T} \mathbf{2}^{4}$ also exhibits anti-HIV activity. As a sugarmodified derivative, cyclobutane nucleoside $3^{5}$ has been synthesized and reported to possess promising anti-HBV activity. In this context, we have envisaged that a novel nucleoside 4, in which the oxetanose ring oxygen of $\mathbf{2}$ is replaced with a geminaldifluoromethylidene $\left(\mathrm{CF}_{2}\right)$ group, would show promising antiviral activities, as the $\mathrm{CF}_{2}$ group has been suggested as an isopolar and isosteric substituent for oxygen. ${ }^{6}$

Intramolecular cyclization of carbon-centered radicals to unsaturated bonds has been widely used for the construction of cyclopentanes or cyclohexanes via 5-exo, 6-exo or 6-endo-trig mode according to Baldwin's rule. ${ }^{7,8}$ In contrast, there have been only a few examples of 4-exo-trig cyclization reactions of 4-pentenyl carbon radicals leading to cyclobutane rings. ${ }^{9}$ Successful ring closures have relied upon the gem-dialkyl effect. ${ }^{9,10}$ During the

${ }^{a}$ School of Pharmacy, Showa University, 1-5-8 Hatanodai,

Shinagawa-ku, Tokyo 142-8555, Japan.

E-mail: kumamoto@pharm.showa-u.ac.jp; Fax: +81-3-3784-8252;

Tel: $+81-3-3784-8187$

${ }^{b}$ Advanced Science Institute, NanomedicalEngineering Laboratory,

RIKEN, 2-1 Hirasawa, Wako-shi, Saitama 351-0198, Japan

${ }^{c}$ Rega Institute for Medical Research, Katholieke Universiteit Leuven,

Minderbroedersstraat 10, B-3000 Leuven, Belgium

${ }^{d}$ Division of Antiviral Chemotherapy, Center for Chronic Viral

Diseases, Graduate School of Medical and Dental Sciences,

Kagoshima University, Kagoshima 89-8544, Japan

$\dagger$ Electronic supplementary information (ESI) available: Experimental procedures for all newly synthesized products. CCDC 895081. For ESI and crystallographic data in CIF or other electronic format see DOI: $10.1039 / \mathrm{c} 2 \mathrm{cc} 35876 \mathrm{j}$
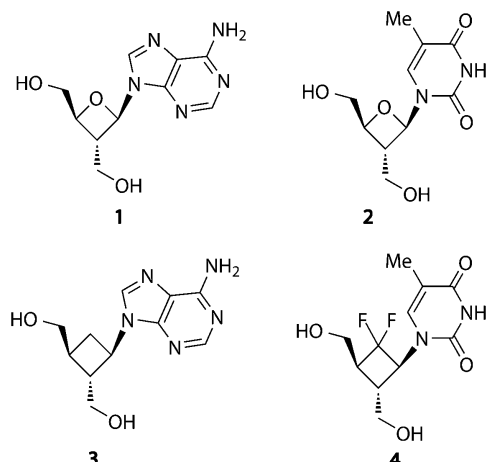

Fig. 1 Structure of compounds 1-4.

course of our synthetic studies of $\mathbf{4}$ by radical cyclization, we found that the electron-withdrawing effect of the fluorine atom facilitates the 4-exo-trig cyclization. In this communication we report these results and their application to the synthesis of $\mathbf{4}$.

There are three possible 4-pentenyl carbon radicals shown as A-C leading to the gem-difluorocyclobutane structure via 4-exo-trig cyclization reaction (Fig. 2). Initially, 5a, which is a precursor of the 1,1-difluoro-4-pentenyl carbon radical $\mathbf{A}$, was reacted with $\mathrm{Bu}_{3} \mathrm{SnH}$ in the presence of AIBN in refluxing toluene. This reaction gave target 6a in $29 \%$ yield (cis/trans $=3 / 1$ ). However, a major product was the reduced product $7 \mathbf{a}$ (32\%). 2,2-Difluoro-carbon-radical B generated from $\mathbf{5 b}$ failed to cyclize and gave a complex mixture.

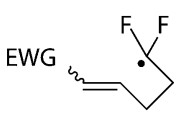

A

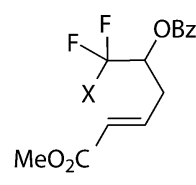

5a $\mathrm{X}=\mathrm{Br}$

$7 a X=H$
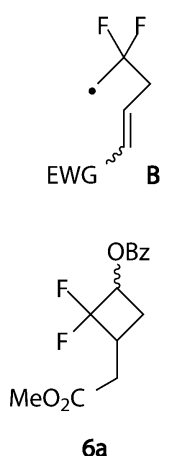

$6 a$

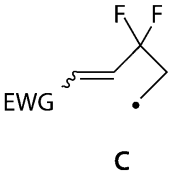

C

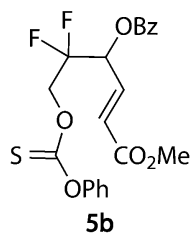

Fig. 2 Plausible radical intermediates A-C and their model compounds. 
Table 1 Radical reaction of $\mathbf{5 c - 5 f ^ { a }}$

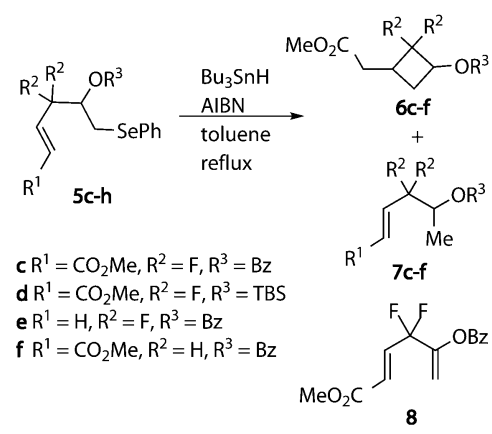

\begin{tabular}{llll}
\hline Entry & Precursor & Yield [\%] of $\mathbf{6}$ (ratio; cis/trans) & Yield [\%] of 7 \\
\hline 1 & $\mathbf{5 c}$ & $72(2 / 1)$ & $12^{b}$ \\
2 & $\mathbf{5 d}$ & $91(2 / 1)^{c}$ & - \\
3 & $\mathbf{5 e}$ & $-2^{d}$ & 72 \\
4 & $\mathbf{5 f}$ & $2^{d}$ & 61
\end{tabular}

${ }^{a}$ Reaction was carried out in refluxing toluene using 2.0 equiv. of $\mathrm{Bu}_{3} \mathrm{SnH}$ and 0.2 equiv. of AIBN (dropwise addition over $4 \mathrm{~h}$ ). ${ }^{b}$ Compound 8 was obtained in $7 \%$ yield. ${ }^{c}$ The ratio was calculated by the integration of ${ }^{1}$ HNMR. ${ }^{d}$ The stereochemistries of $\mathbf{6 f}$ were not determined.

In contrast to these results, when $\mathbf{5 c}$ was subjected to the same reaction conditions for the ring-closure of $\mathbf{5 a}$, intramolecular 4-exo-trig cyclization of the resulting 3,3-difluoro-4-pentenyl carbon radical $\mathbf{C}$ efficiently proceeded to give the target difluorocyclobutane $\mathbf{6 a}$ in $72 \%$ yield (cis/trans $=2: 1$ ), along with the reduction product $7 \mathrm{c}(12 \%)$ and diene $8(7 \%)$ (Table 1, entry 1). As shown in entry 2, TBS-protected 5d gave 6d (cis/trans $=2: 1)$ in $91 \%$ isolated yield. As can be seen in entry 3, the simple alkene 5e lacking the electronwithdrawing group gave reduced product $7 \mathbf{e}$ as a sole product in $72 \%$ yield (entry 3 ). A similar result was obtained in the case of the de-fluorinated analogue $\mathbf{5 f}$ (entry 4). These results suggested that the efficiency of the 4-exo-trig cyclization was dependent upon the electron density of the double bond although the influence of the conformational change of each radical intermediate cannot be ruled out. To validate our assumption, SOMO and LUMO levels of the model intermediates were calculated based on Natural Bind Orbital (NBO) theory Table S1, see ESI. $\dagger$ As anticipated, the energy level of LUMO of $\mathbf{5} \mathbf{c}^{\prime}$ having both two fluorine atoms and unsaturated ester is lower than those of $\mathbf{5} \mathbf{e}^{\prime}$ and $\mathbf{5} \mathbf{f}^{\prime}$ lacking ester or two fluorine atoms. By taking the nucleophilic character of the carbon centered radical into consideration, ${ }^{11}$ it would be reasonable that increasing electrophilicity of the radical-accepting unsaturated bond by fluorine substituents and ester facilitated the 4-exo-trig cyclization.

After optimization of the substrate for the radical cyclization, we have turned our attention to the synthesis of the difluoromethylene analogue 4 of oxetanocin T 2 . For the synthesis of the target molecule, we needed to prepare the radical precursor $\mathbf{1 3}$ and the synthetic route is illustrated in Scheme 1. Initially, Weinreb amide $9^{12}$ was treated with Li-HMDS and subsequently $\mathrm{BOMCl}$ in one pot to give the $\alpha$-benzyloxymethylated product, which was then reduced by DIBAL-H to furnish the aldehyde 10 in $47 \%$ yield. Compound $\mathbf{1 0}$ was subjected to Reformatsky reaction utilizing $\mathrm{BrF}_{2} \mathrm{CCO}_{2} \mathrm{Et}$ and activated zinc ${ }^{13}$ followed by silylation of the resulting secondary alcohol to give $\mathbf{1 1}$ in $77 \%$ yield.

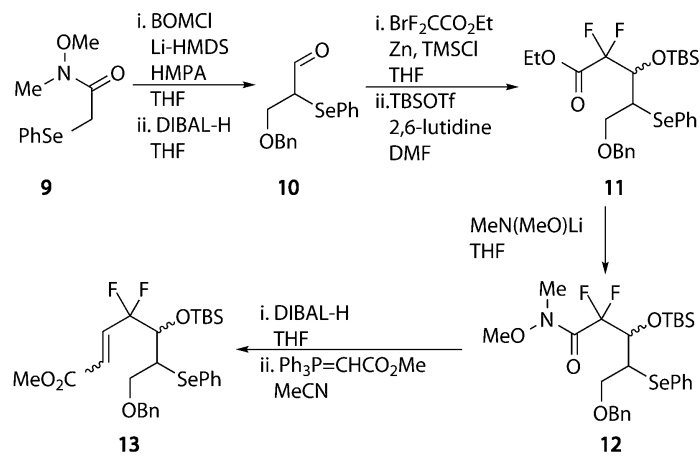

Scheme 1 Preparation of radical precursor 13.

The ester $\mathbf{1 1}$ was then converted into the Weinreb amide $\mathbf{1 2}$ in excellent yield $(90 \%$ yield). DIBAL-H reduction of $\mathbf{1 2}$ and subsequent Wittig reaction gave the desired substrate $\mathbf{1 3}$ [a mixture of three stereoisomers; $c a$. major- $(E)-13$ : minor(E)-13: (Z)-13 = $1: 0.22: 0.14]$.

With the substrate $\mathbf{1 3}$ in hand, we next carried out the radical cyclization and the results are summarized in Table 2. As shown in entry 1 , when 13 was reacted with $\mathrm{Bu}_{3} \mathrm{SnH}$ under the conditions described in Table 1, the yield of the desired difluorocyclobutane derivative $\mathbf{1 4}$ was unexpectedly decreased to $38 \%$ yield (diastereomeric mixture: $c a .2: 1$ ). On the basis of NOE experiments, the major isomer was found to be trans,trans-14 with the minor isomer being trans,cis-14, respectively (see ESI $\dagger$ ). To improve the yield of $\mathbf{1 4}$, the reaction was carried out at ambient temperature using $\mathrm{Et}_{3} \mathrm{~B}$ as an initiator under an $\mathrm{O}_{2}$ atmosphere. As can be seen in entries 2 to 5 , the longer the duration time of the dropwise addition of $\mathrm{Bu}_{3} \mathrm{SnH}$, the better the isolated yield of $\mathbf{1 4}$ although the ratio of trans,trans-14/ trans,cis-14 was unchanged. ${ }^{14}$ The best result was obtained when $\mathrm{Bu}_{3} \mathrm{SnH}$ was added dropwise over $24 \mathrm{~h}$ to give $\mathbf{1 4}$ in $78 \%$ yield (entry 5). No improvement was observed at $-20{ }^{\circ} \mathrm{C}$ due to the recovery of $\mathbf{1 3}(47 \%)$ (entry 6).

Finally, conversion of $\mathbf{1 4}$ to the target $\mathbf{4}$ was performed (Scheme 2). DIBAL-H reduction of an epimeric mixture of $\mathbf{1 4}$ and subsequent phenylselenylation of the resulting hydroxyethyl derivative by using $\mathrm{PhSeCN}$ and $\mathrm{Bu}_{3} \mathrm{P}^{15}$ gave 15 in $97 \%$ yield in two steps. The selenide $\mathbf{1 5}$ was converted to terminal olefin $\mathbf{1 6}$

Table 2 Radical cyclization of $\mathbf{1 3}$

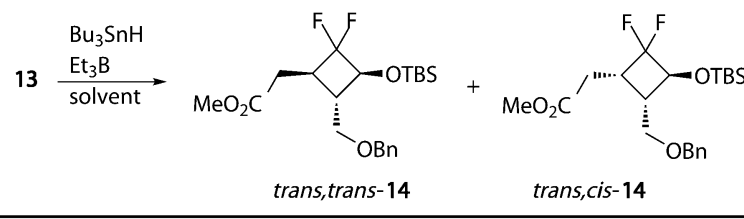

\begin{tabular}{llllll}
\hline Entry & Solvent & $\begin{array}{l}\text { Temp } \\
\left({ }^{\circ} \mathrm{C}\right)\end{array}$ & $\begin{array}{l}\text { Time }^{a} \\
(\mathrm{~h})\end{array}$ & $\begin{array}{l}\text { Yield }[\%] \\
\text { of } \mathbf{1 4}\end{array}$ & $\begin{array}{l}\text { Ratio } \\
\text { trans, } \text { (trans, } \text { trans }\end{array}$ \\
\hline 1 & Toluene & $110^{c}$ & 4 & 38 & $2.0 / 1$ \\
2 & Benzene & $\mathrm{rt}$ & 2 & 72 & $2.7 / 1$ \\
3 & Benzene & $\mathrm{rt}$ & 4 & 70 & $2.7 / 1$ \\
4 & Benzene & $\mathrm{rt}$ & 8 & 77 & $2.6 / 1$ \\
5 & Benzene & $\mathrm{rt}$ & 24 & 78 & $2.6 / 1$ \\
6 & Toluene & -20 & 48 & $48^{d}$ & $3.0 / 1$
\end{tabular}

${ }^{a} \mathrm{Bu}_{3} \mathrm{SnH}$ was dropwise added at an indicated time. ${ }^{b}$ The ratio (trans,trans/trans,cis) was calculated by integration of ${ }^{1}$ HNMR. ${ }^{c}$ AIBN was used as an initiator. ${ }^{d}$ Compound 13 was recovered in $47 \%$. 


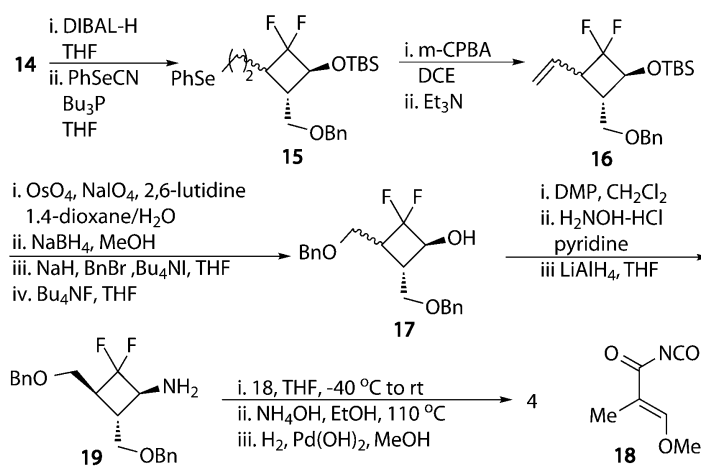

Scheme 2 Synthesis of 4

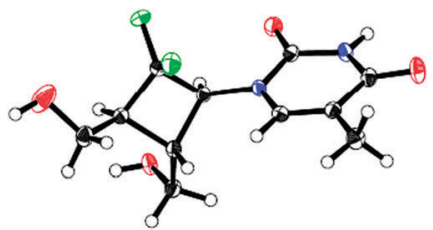

Fig. 3 ORTEP drawing of compound 4.

( $86 \%$ yield) by oxidation with $m$-CPBA and subsequent $s y n$ elimination of the respective selenoxide. Next, $\mathbf{1 6}$ was transformed into 17 (diastereomeric mixture; $c a .3: 1$ ) in $65 \%$ yield through the following four steps: (1) Lemieux-Johnson oxidation in the presence of 2,6-lutidine, ${ }^{16}$ (2) $\mathrm{NaBH}_{4}$ reduction of the resulting aldehyde, (3) benzylation of the primary alcohol, (4) removal of the TBS group by using $\mathrm{Bu}_{4} \mathrm{NF}$. Next, the cyclobutylamine 19 was synthesized through (1) Dess-Martin periodinane (DMP) oxidation of 17, (2) oximation of the ketone, (3) $\mathrm{LiAlH}_{4}$ reduction of the oxime. ${ }^{17}$ Although, the yield was not satisfied (32\%), amine 19 was obtained as a single stereoisomer. Finally, $\mathbf{1 9}$ was transformed into the corresponding thymine nucleoside by a reported procedure ${ }^{18}$ using isocyanate 18. Debenzylation with $\mathrm{Pd}(\mathrm{OH})_{2} / \mathrm{C}$ gave the title compound 4 in $56 \%$ yield. The relative stereochemistry of $\mathbf{4}$ was assigned by NOE experiments (see ESI $\dagger$ ) and confirmed by X-ray crystallographic analysis (Fig. 3).

It was found that the 4-exo-trig cyclization reaction of the 3,3difluoro-4-pentenyl carbon radical efficiently proceeded to furnish the novel gem-difluorocyclobutane. The electron withdrawing effect of the two fluorine atoms adjacent to the radical accepting double bond accelerated the cyclization reaction. As a synthetic application of this radical ring closure, the synthesis of difluoromethylene oxetanocin T 4, a potential anti-viral agent, was achieved. Anti-viral assay revealed that compound $\mathbf{4}$ did not show any activity against HIV-1, VZV and HCMV.

The authors are grateful to Ms Y. Odanaka and S. S. Matsubayashi (Center for Instrumental Analysis, Showa University) for technical assistance with NMR spectroscopy, MS and elemental analysis. Financial support from the Japan Society for the Promotion of Science (KAKENHI No. 21590123 to K.H.) is gratefully acknowledged.

\section{Notes and references}

1 N. Shimada, S. Hasegawa, T. Harada, T. Yomisawa, A. Fujii and T. Takita, J. Antibiot., 1986, 39, 1623.

2 (a) H. Hoshino, N. Shimizu, N. Shimada, T. Takita and T. Takeuchi, J. Antibiot., 1987, 40, 1077; (b) N. Shimada, S. Hasegawa, S. Saito,
T. Nishikiori, A. Fujii and T. Takita, J. Antibiot., 1987, 40, 1788; (c) J. Seki, N. Shimada, K. Takahashi, T. Takita, T. Yakeuchi and H. Hoshino, Antimicrob. Agents Chemother., 1989, 33, 773.

3 (a) T. Nagahata, K. Araki, K. Yamamura and K. Matsubara, Antimicrob. Agents Chemother., 1992, 36, 2042; (b) E. Ichikawa and K. Kato, Antimicrob. Agents Chemother., 1994, 38, 707.

4 J. Alder, M. Mitten, D. Norbeck, K. Marsh, E. R. Kern and J. Clement, Antiviral Res., 1994, 23, 93.

5 E. V. Genovesi, L. Lamb, I. Medina, D. Taylor, M. Seifer, S. Innaimo, R. J. Colonno and J. M. Claek, Antiviral Res., 2000, 48, 197.

6 (a) G. M. Blackburn, D. A. England and F. Kolkmann, J. Chem. Soc., Chem. Commun., 1981, 930; (b) G. M. Blackburn, D. Brown and S. J. Martin, J. Chem. Res., Synop., 1985, 92; (c) G. M. Blackburn, F. Eckstein, D. E. Kent and T. D. Perree, Nucleosides Nucleotides, 1985, 4, 165; (d) G. M. Blackburn and D. E. Kent, J. Chem. Soc., Perkin Trans. 1, 1986, 913; (e) G. M. Blackburn, T. D. Perree, A. Rashid, C. Bisbal and B. Levleu, Chem. Scr., 1986, 26, 21; (f) G. M. Blackburn, D. Brown, S. J. Martin and M. J. Parratt, J. Chem. Soc., Perkin Trans. 1, 1987, 181 for recent examples of $\mathrm{CF}_{2}$ containing nucleosides, see:; $(g)$ Y.-Y. Yang, W.-D. Meng and F.-L. Qimg, Org. Lett., 2004, 6, 4257; (h) Y.-Y. Yang, J. Xu, Z.-W. You, X.-H. Xu, X.-L. Qiu and F.-L. Qing, Org. Lett., 2007, 9, 5437; (i) H. Kumamoto, K. Haraguchi, M. Ida, K. T. Nakamura, Y. Kitagawa, T. Hamasaki, M. Baba, S. S. Matsubayashi and H. Tanaka, Tetrahedron, 2009, 65, 7630 .

7 For general reviews, see: (a) A. L. J. Beckwith, Tetrahedron, 1981, 37, 3073; (b) A. Srikrishna, Curr. Sci., 1987, 56, 392; (c) M. Ramaiah, Tetrahedron, 1987, 43, 3541; (d) P. Curran, Synthesis, 1988, 417.

8 J. E. Baldwin, J. Chem. Soc., Chem. Commun., 1976, 734.

9 For examples, see: (a) S.-U. Park, T. R. Varick and M. Newcomb, Tetrahedron Lett., 1990, 31, 2975; (b) K. Ogura, N. Sumitani, A. Kayano, H. Iguchi and M. Fujita, Chem. Lett., 1992, 1487; (c) M. E. Jung, I. D. Trifunovich and N. Lensen, Tetrahedron Lett., 1992, 33, 6719; (d) M. E. Jung and J. Gervay, J. Am. Chem. Soc., 1991, 113, 224; (e) M. E. Jung, R. Marquez and K. N. Houk, Tetrahedron Lett., 1999, 40, 2661; $(f)$ M. E. Jung, Synlett, 1999 , 843; (g) D. Johnston, C. M. McCusker and D. J. Procter, Tetrahedron Lett., 1999, 40, 4913; (h) D. Johnston, C. M. McCusker, K. Muir and D. J. Procter, J. Chem. Soc., Perkin Trans. 1, 2000, 681; (i) D. Johnston, N. Francon, D. J. Edmonds and D. J. Procter, Org. Lett., 2001, 3, 2001; (j) D. J. Edmonds, K. W. Muir and D. J. Procter, J. Org. Chem., 2003, 68, 3190; (k) H. Y. Harb, K. D. Collins, J. V. Garcia Altur, S. Bowker, L. Campbell and D. J. Procter, Org. Lett., 2010, 12, 5446; (l) H. Y. Harb and D. J. Procter, Synlett, 2012, 6.

10 (a) R. M. Beesley, C. K. Ingold and J. F. Thorpe, J. Chem. Soc. Abstr., 1915, 107, 1080; (b) C. K. Ingold, J. Chem. Soc. Abstr., 1921, 119, 305; (c) R. F. Brown and N. M. VanGulick, J. Org. Chem., 1956, 21, 1046; (d) P. von R. Schleyer, J. Am. Chem. Soc., 1961, 83, 1368.

11 B. Giese, Angew. Chem., Int. Ed. Engl., 1983, 22, 753.

12 S. Baeluenga, E. Moulin, P. Lopez and N. Winssinger, Chem.-Eur. J., 2005, 11, 4935

13 (a) A. Otaka, J. Watanabe, A. Yukimasa, Y. Sasaki, H. Watanabe, T. Kinoshita, S. Oishi, H. Tamamura and N. Fujii, J. Org. Chem., 2004, 69, 1634; (b) M. Schuler, F. Silva, C. Bobbio, A. Tessier and V. Gouverneur, Angew. Chem., Int. Ed., 2008, 47, 7927; (c) Y.-K. Chang, J. Lee, G.-S. Park, M. Lee, C. H. Park, H. K. Kim, G. Lee, B.-Y. Lee, J. Y. Baek and K. S. Kim, Tetrahedron, 2010, 66, 5687.

14 The ratio of trans,trans/trans,cis-14 was varied between $(E)$ - and $(Z)$-13: $2.6 / 1$ for $(E)$ - and $1 / 1$ for $(Z)$-isomer (see ESI $\dagger$ ).

15 P. A. Grieco, S. Gilman and M. Nishizawa, J. Org. Chem., 1976, 41, 1485.

16 W. Yu, Y. Mei, Y. Kang, Z. Hua and Z. Jin, Org. Lett., 2004, 6, 3217.

17 For a direct introduction of thymine base into 17 in an $\mathrm{S}_{\mathrm{N}} 2$ manner, inversion of configuration of the secondary hydroxyl was attempted by Mitsunobu conditions or oxidation-reduction sequence. However, all met failure.

18 (a) R. Csuk and Y. von Scholz, Tetrahedron, 1995, 51, 7193; (b) P. Wang, L. A. Agrofoglio, M. G. Newton and C. K. Chu, J. Org. Chem., 1999, 64, 4173. 